\title{
Internal Governance Dilemma and Rational Regression in Higher Vocational Colleges: Based on Perspective of System Theory*
}

\author{
Yonghong Ao \\ Chengdu Industrial Vocational Technical College \\ Chengdu, China 610218
}

\author{
Hui Li \\ Chengdu Industrial Vocational Technical College \\ Chengdu, China 610218
}

\begin{abstract}
The internal governance of higher vocational colleges is faced with such realistic dilemmas as imbalance of governance structure, crowding out of governance power, and single governance subject. The internal governance of higher vocational colleges has systemic characteristics such as integrity, hierarchy and openness. Based on the perspective of system theory, the innovative path of internal governance of higher vocational colleges should be explored: combing governance concepts, balancing governance power, optimizing governance structure, innovating governance mechanism and shaping governance culture.
\end{abstract}

Keywords-internal governance; system theory; higher vocational colleges; governance culture

\section{INTRODUCTION}

At present, socialism with Chinese characteristics has entered a new era, and China's higher vocational education has also changed from "seeking large quantities" to "seeking strong quality" and entered a high-quality "connotative decoration" stage. The goal and task of high-quality development in higher vocational colleges is to build a modern governance system that takes people as the logical orientation, the rule of law as the premise guarantee, the common governance as the path strategy, and the good governance as the ultimate goal. However, due to historical conditions and practical factors, internal governance of higher vocational colleges has many problems in governance structure, governance power, governance mechanism, governance culture and other elements; structure and environment, which no longer meet the needs of higher vocational education development and economic and social development. As a system engineering, the internal governance of higher vocational colleges needs to use system theory to break through one-sided thinking and close vision, solve the difficult problems of construction and development, and explore the governance path of reform and innovation.

*Fund: Financed by Sichuan Key Research Base of Humanities and Social Sciences -Sichuan Education Development Research Center Project (CJF17011).).
II. THEORETICAL BASIS: INTERNAL GOVERNANCE OF Higher Vocational COLleges FrOM THE PeRsPeCtive OF SYSTEM THEORY

\section{A. The Connotation and Application of System Theory}

System theory, which originated in the field of natural science, is an interdisciplinary theory established and developed by Austrian-American theoretical biologist L. Von. Bertalanffy under the scientific and philosophical background of modern western analytical tradition and logical norms. The system theory holds that any system is composed of several interrelated parts (elements) and has a specific structure and function as an organic whole [1]. From a dynamic point of view, the system is a group of interconnected things, in a certain period of time, with a specific pattern of behavior affect each other to achieve a certain goal; from a static point of view, the system is composed of several components that interact and depend on each other, and has specific functions [2].

The system theory regards the object studied and processed as a system, analyzes the structure and function of the system, studies the interrelation and regularity of changes among the system, elements and environment, effectively has solved the dialectical relationship between the subjectivity and objectivity, relativity and absoluteness of cognition, has avoided the one-sidedness between the subjectivity and objectivity, relativity and absoluteness of cognition [3], and has become "public knowledge" transplanted and applied among many discipline fields such as management, sociology and culture, and has widely applied in the research of education field. It has achieved a breakthrough in epistemology, regarding the research object as an overall system composed of microscopic elements, miso-level structure and macro-level environment, and thus studying the laws of overall development and change of things. It has also achieved a breakthrough in scientific research methodology. It has made people realize the complex and non-linear relationship between things, turning their attention from studying factors or behavioral manifestations to exploring the internal structural relationship of the system, thus starting to try to construct an overall and comprehensive research model. 


\section{B. System Characteristics of Internal Governance in Higher Vocational Colleges}

Based on the perspective of system theory, the internal governance of higher vocational colleges is not only an integral part of the whole educational governance system, but also an independent system different from other types of educational governance. It has system attribute characteristics such as integrity, hierarchy and openness.

The first is integrity. Integrity is the core of system theory. The system theory holds that the system exists and functions as an organic whole composed of many elements. It is not a simple mechanical combination and the addition of elements [4], and has the overall characteristics that some parts do not have in an isolated state. The integrity of the system requires people to grasp the relationship between the whole and the part, the whole and the level, the whole and the structure, and the whole and the environment from the overall perspective. The internal governance of higher vocational colleges should pay attention not only to the organization but also to the management process. Both organizational goals and human factors should be emphasized so as to grasp, coordinate and advance the whole.

The second is hierarchy. The system does not exist in isolation. Any system is always in a ring in the system ladder series, and its system structure must show multi-level characteristics. Different levels of systems have different attributes, structures and functions. The higher the level, the more complex its attribute, structure and function will be. The more orderly the system is, the more organized and stable it is. The internal governance of higher vocational colleges must take the clear hierarchy as the basic requirement, carry out necessary coordination, intervention and transformation on the system hierarchy, adjust the proportional relationship between the system hierarchy and the elements, make the hierarchy move according to their respective functions and follow the overall goal of the system, and ensure the real unity of the system from hierarchy form to hierarchy content.

The third is openness. Any organization or thing is interrelated and interacts with a specific environment. The system always exists in a certain environment and exchanges materials, energy and information with other systems as the environment [5]. In this exchange, the system goes through a dynamic process of continuous optimization from low level to high level, from simple to complex, and from disorder to order. The internal governance of higher vocational colleges must look at the system, grasp the system and coordination system with an open eye, connect the outside world with an open attitude, pay attention to the development trend of economy and society, follow the development rules of higher vocational education, fully consider the demands of stakeholders, break the boundary, integrate in multiple ways, and form resultant force.

\section{REAL DILEMMA: ANALYSIS OF INTERNAL GOVERNANCE IN HigHER VOCATIONAL COLLEGES}

\section{A. "Separation" of Constitution Formulation and Actual Implementation}

Governing a school according to law is the logical basis of internal governance in higher vocational colleges, which is not only an important part of building a socialist country ruled by law, but also an inevitable requirement for realizing educational modernization [6], at the same time, it is also an objective need for higher vocational colleges to improve the scientific level of governance. The Ministry of Education's "Outline for Comprehensively Promoting the Implementation of Governing Schools by Law" clearly points out that "the concept of equality before laws, regulations and rules should be firmly established, and fair, legal and systematic systems and procedures should be established to ensure that the school's purpose, educational activities and system norms conform to the requirements of the socialist legal concept of democracy and the rule of law, freedom and equality, fairness and justice" and "the ability to use legal thinking and legal means to solve outstanding contradictions and problems in the reform and development of schools should be enhanced". The constitution is a normative text with the most systematic and integral characteristics and certain legal effects. It inherits the national education laws and regulations and opens up the internal rules and regulations of colleges and universities [7]. It is endowed with such important missions as optimizing the internal governance structure, realizing common governance, and ensuring the autonomy of running schools. It fully embodies the school management logic and thoughts of modern governance of higher vocational colleges and becomes the basic program of modern governance of higher vocational colleges. However, the formulation of the articles of association is mainly driven by policies, rather than based on the internal reform and development needs of higher vocational colleges. As a result, the implementation of the articles of association lacks specific implementing agencies and basic operating rules. The overall grasp of the articles of association is bogged down in a dilemma and overall consideration becomes empty talk. The articles of association become a simple text decoration, which results in chaos such as supremacy of power, system decoration, neglect of planning, attention to the present, disregard of procedures and neglect of the rights and interests of teachers and students.

\section{B. Allocation of Power and "Crowding Out" of Actual Implementation}

There are mainly political power, administrative power, academic power and democratic power in higher vocational colleges. Political power is mainly realized through party committees, administrative power is mainly realized through the president's office meeting, academic power is mainly realized through academic committees, and democratic power is mainly realized through staff representative conferences. Among them, political power lies in publicizing the Party's thoughts and purposes, ensuring the leadership of the Party and the direction of running a socialist school, 
grasping the development direction of the school and leading the school work in a unified way. The administrative power lies in the realization of the power of management and the power of presiding over administrative affairs through the division of responsibilities of the principal under the leadership of the Party committee. The principal is fully responsible for the teaching, scientific research and other administrative work of the school. Academic power is the concentrated embodiment of the teachers' subjective status in higher vocational colleges, which is manifested in academic consultation, academic deliberation and academic decisionmaking. Democratic power lies in teachers and students reviewing major school decisions and policies on the interests of teachers and students through democratic elections, proposals, permanent representatives, trade union construction and other operational mechanisms. Judging from the internal governance system of higher vocational colleges, these four powers need to be rationally allocated, coordinated and balanced to jointly promote the effective operation of various functional departments and organizations in the system. However, in the actual implementation process, the power structure was reversed, and the whole system was full of administrative color, showing a "pan-administrative" state. The organizational form took power consciousness as the operating value basis and control as the starting point of the basic behavior. Administrative power replaces academic power, administrative decision replaces academic decision, academic activities are excessively interfered, and the management of academic affairs and teaching affairs tends to be bureaucratic. Supervision power is seriously lacking, democratic supervision has evolved into formal supervision, and supervision results have evolved into leadership will. On the whole, the internal power allocation in higher vocational colleges presents the phenomena of power conflict, power crowding and power generalization.

\section{The "Split" Between Open and Common Governance and Actual Operation}

As a subsystem, there is a direct or indirect relationship between the internal governance of higher vocational education and other systems of educational governance. On the one hand, it acts on other systems; on the other hand, it is subject to other systems. That is, while the internal governance of higher vocational education has social functions, its development requires certain external conditions. According to the observation of the experience world, the social relationship structure in which higher vocational colleges are located has typical intersection. It exists in the transition space from simple human resources to practical human resources, as well as in the "melting pot" where educational functions and industrial needs permeate each other and are highly integrated. As a kind of education type that is most closely related to economic and social development, higher vocational education is the main position to cultivate "first resources" of human resources, and industrial enterprises are the important recipients of "products" of higher vocational colleges. The two are interdependent, mutually restricted and coordinated. The closeness and interaction between higher vocational education and economic and social development determine the openness of diversified education in higher vocational colleges. However, in actual operation, higher vocational colleges can complete the supply of vocational education resources only by satisfying administrative orders, resulting in the path dependence of higher vocational colleges on the administrative system, naturally reducing the attention to market information and industrial dynamics, and reducing the initiative, timeliness and accuracy of obtaining external information, thus weakening the relevance and relevance with regional economic development and industrial demand, making it difficult for social forces to enter the field of higher vocational education, making it impossible for enterprises to effectively play the role of important schoolrunning subjects and to fully integrate into the talent training links such as cooperative school-running, professional planning, textbook development, scientific and technological transformation, and so on, and the overall school-running is still dominated by "unit".

\section{STRATEGIC CHOICE: THE PATH EXPLORATION OF INTERNAL GOVERNANCE IN HIGHER VOCATIONAL COLLEGES}

\section{A. Setting up the Concept of Governance}

"Governance" as a new paradigm of contemporary public management, its value appeal lies in the realization of winwin and the pursuit of good governance through full cooperation and collaborative innovation among multiple subjects. The internal governance of higher vocational colleges is to fully respect the interest expression and interest demands of various stakeholders. In the process of pursuing "positive and game", in order to realize the "maximum common divisor" of the interest expression and interest demands of various stakeholders, the organic unity and benign interaction of each other's duties, responsibilities, rights and interests are realized.

At present, higher vocational education has entered a stage of high-quality development. Its organization is becoming more complicated, its structure is diversified, its level is differentiated, its rights and interests are diversified, and its democratic demands are increasing. The internal governance of higher vocational colleges is changing from micro-management to macro-management, from direct management to indirect management, and from management to service. The changes in the external environment of higher vocational education and its own development trend require us to grasp the characteristics of integrity, hierarchy and openness of the system, explore the innovative path of internal governance in higher vocational colleges, promote the management of schools according to law with the articles of association as the core, lead the development of schools with strategic planning as the leader, promote the democratic and scientific decision-making ability, the open and rule of law implementation ability, the coordination and coordination of regulation ability, and the interactive and cooperative cooperation of coordination ability, so as to realize the interest balance of multi-stakeholder and ensure the orderly development of higher vocational colleges. 


\section{B. Balance Governance Power}

One is to return to academic standard. Higher vocational colleges, like other universities, are essentially academic institutions. Teaching knowledge, creating knowledge, developing science and technology, and inheriting culture are not only their academic needs, but also the cultural spirit that schools should have. At present, the boundary between higher vocational colleges and industry and market is gradually blurred. More importantly, it is necessary to break through the traditional thinking of "external shaping" of power allocation and seek the endogenous mechanism of power generation. Based on the essential characteristics of academic nature, the academic management is coordinated with the academic committee as the core. The academic committee consists of specialized research institutions such as teaching committee, professional construction committee, quality evaluation committee and professional and technical post evaluation committee. At the same time, according to the "professional" characteristics of higher vocational colleges, it is necessary to build "industrial college" and "school-enterprise cooperation innovation center" with industry enterprises and scientific research institutions to activate the academic power with teachers as the main body.

The second is to pay attention to the "three powers" overall planning. Do a good job of "decentralization", adhere to the principal responsibility system under the leadership of the party Committee, straighten out the relationship between the party and the government, the school and the hospital, the administrative power and the school administration, change the phenomenon of "governance inversion" which used to be too lenient and too fine, and focus on direction control and strategic management. We should do a good job in "delegating power", focus on "grasping the big and putting the small" and minimize the management of micro-affairs at the school level, build higher vocational colleges under the rule of law and service-oriented higher vocational colleges, give full play to the important role of the party and government "hands of support" and "hands of inaction" in the allocation of resources, and fully mobilize the enthusiasm and innovation of functional departments and secondary departments. Do good jobs in "supervising power", establish an internal control system, and use comprehensive policy tools such as laws, planning, standards, funds, monitoring, evaluation, supervision, rectification, etc. to establish and improve the evaluation system of development results, carry out scientific guidance and accountability, and form a virtuous circle of "carrying out duties, responsibilities and supporting each other".

\section{Optimizing the Governance Structure}

First, in the vertical structure, strengthen hierarchical governance. As an important organization in higher vocational colleges, secondary colleges and departments undertake many functions such as personnel training and serving the society, which push the management center down to secondary colleges and departments and further expand the scope and autonomy of secondary colleges and departments. It sorts out the scope of responsibilities and power boundaries of secondary departments, and clarifies the autonomy of secondary departments in the selection and employment, assessment and distribution, school-enterprise cooperation, professional construction and other aspects of the department [8]. And it also strengthens the cohesion and unity of the secondary departments, explores the construction of the articles of association of the secondary departments, and promotes the secondary departments to become the main body of teaching, scientific research and social service.

Secondly, in the horizontal structure, the structure "Separation of handling and evaluation". The decisionmaking organization, executive organization, consulting organization and supervision organization in higher vocational colleges form an "handling" system. At the same time, a third-party evaluation organization is introduced to participate in the governance evaluation, forming an "evaluation" system, which provides objective evidence for higher vocational colleges to sense their own pulse and ensures the scientific and fair operation of the decisionmaking system. The separation, division of labor, interaction and coordination of "handling" and "evaluation" have become a closed-loop system that affects and promotes each other. The "separation" of the two governance structures is more conducive to the refinement of post responsibilities, the standardization of internal institutions, and the promotion of more rational internal governance in higher vocational colleges.

\section{Innovative Governance Mechanism}

The first is to establish a multi-subject decision-making mechanism involving government, industry, enterprises and schools. No matter which system, only by ensuring its own openness can it truly keep the system alive; Only "both internal and external repair" can make the operation of power more orderly and transparent; . Strengthen the management of the allocation of vocational education resources, decompose the power of resource allocation, improve the coordination mechanism to attract and gather high-quality educational resources, improve the construction of sharing platforms, and improve the efficiency of resource utilization. According to the basic principles of "government-led, industry guidance, enterprise participation, school implementation, and common development", a council is formed to coordinate the participation of "government, industry, enterprise, and school" parties in the management of public affairs in higher vocational colleges, to change the past reliance on the government alone, to break closed boundaries, to open communication channels, to strengthen close ties with regional industries, and to give full play to the advisory and guiding role of the council, so as to enable all governance entities to form a joint force.

The second is to establish a project management mechanism. Breaking through the barriers of the original departments, the disadvantages of centralized power and the difficulties of low efficiency, the project team is formed through specific service projects to redistribute resources and regroup power. The project team consists of professional teachers, members of vocational education research institutes and other personnel on campus, as well as relevant personnel from industries, enterprises, scientific research institutes and 
various forces such as government, industry, enterprise and society. Over-emphasizing and highlighting one aspect will lead to imbalance. To achieve relative rationality and balance, we must plan in the context of the system, taking into account the particularity of the object of governance and the organizational attributes of the multi-stakeholders, so as to achieve the "party leadership, principal responsibility, professorship, democratic management, social participation" multi-agent collaborative governance model, and gradually moves toward consensus governance and cooperation and governance.

\section{REFERENCES}

[1] E-xiang Luo, Ruizhi Wu. Empirical Study on Enterprise Innovation Capability Based on System Theory [J]. Industrial Technology and Economy, 2012,31(07):154-160.

[2] Jin Han, Zeng Ye. Construction of Performance Evaluation Index System for Discipline Construction in Local Universities Based on System Theory [J]. journal of Zhanjiang normal college, 2012,33(06):165-168.

[3] Shaohua Huang. Comments on Bertalanffy's System Epistemology [J] Journal of Lanzhou University, 1995(02):65-71.

[4] Bin Qin. Analysis of the Path of Macao's Administrative Reform from the Perspective of System Theory [J]. Journal of systems science, 2013,21(03):50-53.

[5] Xiaojun Huang, Yuqin Liu. Predicament and Breakthrough of School Physical Education in China Based on System Theory [J]. Journal of Jilin Institute of Physical Education, 2019,35(03):60-66.

[6] Zelin Liu, Research on Construction of Teacher Self-discipline Mechanism [J] Shanxi Youth, 2019, (03):55-57.

[7] Chong Ye. Predicament and Outlet of Local Newly-built Undergraduate Colleges and Universities Governing by Law [J]. Journal of Langfang Normal University (Social Science Edition), 2015,31(03):103-105+113.

[8] Jie Ma, Junping Zhang, Zisheng Deng. "Internal Governance Reform and Practice of Higher Vocational Colleges with Decentralization, Balance and Synergy [J]. Vocational and Technical Education, 2019,40(05):11-15.

[9] Yue Qiu. Research on the Construction of College Student Associations [D]. Liaoning University, 2019. Kap-lan and Tierney show that the effectiveness of university governance is not a simple linear relationship with the governance system, and the effectiveness of governance is more closely related to cultural factors outside the system. Only the desire to pursue excellence, the state of mind beyond utility, and the mind of helping someone realize his dream, which can make up for the defects of the system. Higher vocational colleges should focus on their own longterm development, integrate social commonness with their own individuality, integrate their own tradition with modern innovation, build core values together, manifest common behavior norms, internalize common inner attitudes, ideological realm and ideal pursuit, integrate and dissolve contradictions among themselves, reach consensus, effectively prevent the generalization of administrative power and alienation of academic power, and thus achieve effective common governance.

\section{CONCLUSION}

Governance is always a process. Internal governance in higher vocational colleges is the result of multiple considerations between higher vocational colleges and 